\title{
Effect of Geogebra on Pre-Service Teachers' Achievement and Perception of Circle Theorems at E. P. College of Education, Bimbilla-Ghana
}

\author{
Anas Seidu Salifu \\ Senior Tutor, Department of Mathematics and ICT Education \\ E.P. College of Education, Bimbilla
}

\begin{abstract}
The study determined the effects of Geogebra on pre-service teacher's achievement and perception in circle theorems. The study was carried out in Evangelical Presbyterian (E.P.) College of Education, Bimbilla. Three research questions were formulated to guide the study. A sample size of $\mathbf{8 8}$ pre-service teachers (PSTs) was used. The control and experimental groups had 45 and 43 pre-service teachers respectively. The study used a quasi-experimental design. Data were collected from the subjects and analyzed quantitatively using SPSS version 18 on the close-ended questionnaire and the achievement pre-test and post-test. The pretest and post-test were analyzed using an independent sample t-test while the perception questionnaire used percentages, mean, and standard deviation in the analysis. Results from the study revealed that students taught circles theorem with Geogebra teaching strategy achieved a higher mean score than those taught through the conventional method with large effect size. The experimental group showed a positive interest in the Geogebra teaching strategy of teaching circles. The paired sample t-test also confirmed that the experimental group gained a mean difference of 9.83 in post-test with a large effect size too. The study recommends the integration of Geogebra into the teaching of circle concepts and theorems at the colleges of education in Ghana.
\end{abstract}

Keywords:- Geometry, Circle theorem, Geogebra, Experimental group, Pre-service teachers, Control group.

\section{INTRODUCTION}

The present educational processes are changing quickly in response to technological advancement (Royati, Ahmad \& Rohani, 2010). Information Communication Technologies (ICT) tools are currently transforming the teaching and learning of Mathematics instructions across the world. This is partly because these tools present indepth opportunities for the understanding of mathematical concepts and theorem. Hohenwarter and Jones (2007) reported that when Geogebra software, for example, was integrated into instruction, students were able to visualize mathematical structures and concretize its abstract nature. According to Dogan (2010), ICT tools increase motivation, understanding, and eliminate teacher-centered approaches of learning Mathematics. Students can then do self- exploration to construct mathematical knowledge and skills when engaged in dynamic geometric software such as Geogebra and geometer sketchpad (Shadaan \& Leong, 2013).

In order to respond to this emerging shift towards ICT integration, the government of Ghana, through the Ministry of Education, launched a blueprint called the ICT Policy in Education in November 2008. As part of the enforcement of the policy, the Government of Ghana initiated (1) the one student one Laptop Project, (2) the training of teachers on ICT integration at all levels of education, (3) connections of some schools to the internet and (4) the supply of computers in schools for effective teaching and learning of all subjects. For mathematics education, the policy pointed out that teachers are to ensure that they incorporate ICT into teaching and learning of all topics in mathematics. Studies have however revealed that such an instructional shift has been quite difficult for teachers. Most teachers still do not integrate ICT tools in the teaching practice because there remains little evidence exemplifying how effective various ICT tools are in Ghanaian classrooms (Akayuure, Nabie \& Sofo, 2013).

From literature elsewhere, Geogebra is said to better fit into the geometry curriculum because it allows students to visualize hidden concepts, and see changes in figures when dragging. Geogebra is also much helpful because it discourages rote learning, where students memorize formulas and apply them without understanding the underlying concepts. In fact, teaching with Geogebra appears to be one of the most fashionable ways of teaching for higher geometric performance.

\section{$>$ Statement of the problem}

Pavethira and Leong (2017) state that "Learning geometry may not be easy and a large number of students fail to develop an adequate understanding of geometry concepts, geometry reasoning, and geometry problemsolving skills" (p.67). The poor performance of pre-service teachers in Colleges of Education in geometry over the years appears to support Pavethira and Leong (2017). Indeed, poor performance has become a great concern for geometry tutors in the Colleges of Education in Ghana. The records from the Institute of Education, University of Cape Coast, Ghana are ample proof to support the problem that students are not performing well in Geometry. In 2013 for 
example, out of 7,449 pre-service teachers who sat for Geometry paper, 1,965 representing $26.4 \%$ got very weak grades (grade D+ and D) (Institute of Education, Professional board report UCC-Ghana, 2013). It was also reported that $926(12.4 \%)$ of the pre-service teachers who failed the geometry paper needed to resit and pass the paper in order to progress from level 100 to level 200. The minimum mark scored by the pre-service teachers was 27.4 out of a total of 100 marks. In 2015, a total of 10348 preservice teachers sat for geometry paper. The failure rate went to $28.8 \%$ (2360) with $42.3 \%$ (4380) obtaining very weak grades (D+ and D) (Institute of Education, Professional board report UCC-Ghana,2015). The minimum mark scored by the pre-service teachers was 24.6 out of a total of 100 marks. Extensive analyses of written scripts over a period of seven years (2009 to 2015) revealed that basic concepts in angle geometry appears to be problematic and accounted for the failure or weak achievement in the geometry papers.

The poor performance has affected pre-service teachers' progress from level 100 to level 200 in Colleges of Education in Ghana. The traditional way of teaching geometry is difficult because pre-service teachers are often not able to visualize and explore the various circle theorems leading to memorization of formulae without understanding. According to Idris (2006), geometry language, visualization abilities, and ineffective instruction result in a lack of understanding which discourages students and results in poor performance. Part of the problem which students face in geometry is when $3 \mathrm{D}$ shapes like cones, pyramids, cylinders, and prism are presented in 2D forms on a conventional chalkboard for them to visualize and solve (Olkun \& Aydogdu, 2003).

To overcome these problems, Geogebra is noted in the literature to facilitate visualization of $3 \mathrm{D}$ in a practical manner on the screen. In Geogebra instruction, pre-service teachers can visualize and absorb the geometry knowledge effectively which should influence their future teaching upon completion. The introduction of ICT tools like Geogebra is proven to be the most appropriate software for addressing geometry teaching and learning across the world. While such ICT tools are recommended for teaching mathematics at colleges of education in Ghana, tutors still do not integrate existing ICT tools in their classroom practice. For instance, no study examined how Geogebra could facilitate understating of circle concepts and theorems or how pre-service teachers view the use of Geogebra in teaching circle concepts/theorems most especially in Northern Region of Ghana. Hence, the motivation to do this study entitled "effect of Geogebra on pre-service teachers' achievement and perception of circle theorems at E.P. College of Education, Bimbilla". It is hoped that the approach will help bring about improvement in performance and excitement in the teaching and learning of geometry.

\section{$>$ Purpose of the study}

The purpose of this study is to investigate the effect of using Geogebra Teaching Strategy (GTS) on pre-service teachers' achievement and perception in circle theorem.

\section{$>$ Research Questions}

- Is there a significant difference in pre-test achievement between the control group and the experimental group in circle theorem?

- Is there any significant effect of Geogebra Teaching Strategy on pre-service teachers' understanding of circle theorems when compared with the conventional approach in the post-test?

- What are pre-service teachers' perceptions about the use of Geogebra in learning of circles theorem?

\section{$>$ Research Hypotheses}

- There is no significant difference in pre-test achievement between the control group and the experimental group.

- There is no significant difference in the post-test between the conventional approach and the Geogebra Teaching Strategy on pre-service teachers' understanding of the circle theorems group.

\section{LITERATURE REVIEW}

Change, in general, is very difficult to achieve, most especially those that involve technology in Education. Current literature points to the fact that there is little evidence to conclude that teachers are using those technological tools to effect the needed transformation. For example, in Ghana, ICT integration policy which was formulated in 2008 to ensure ICT literacy and integration through continuous training of teachers is yet to be properly implemented. In Colleges of Education in Ghana, it is mandatory to incorporate ICT into teaching and learning of Mathematics contents and methodology courses (Institute of Education, UCC, Revised draft syllabus, 2014).

There is ample proof that several and most recent literature reviewed suggests that Geogebra has a great potential future on the academic performance of students in mathematics. For instance, Sharifah and Hutkemri's (2017) study, which examined the effects of Geogebra on students' conceptual and procedural knowledge, concluded that Geogebra can improve students' conceptual and procedural learning of functions. The quasi-experimental approach was used where the sample composed of 176 students in the conventional method group and 169 students in the Geogebra method group. The findings revealed that students who used Geogebra had higher mathematical conceptual and procedural knowledge compared to students with conventional methods. In the same vein, a study by William, Charles, and Adesope (2017) reported that there was a significant difference in means between the control and experimental groups with a sample of 60 students which was in favor of the experimental group. The study design was quasi-experimental where the subjects were purposively selected. The instruments used were 
questionnaires and achievement tests. The study recommended that teachers should not ignore technology integration in their classrooms.

Nazihatulhasanah and Nurbiha (2015) study used a quasi-experimental design consisting of experimental and control groups in statistics. The purpose was to investigate the effectiveness of Geogebra with 62 students who were divided into experimental groups (Geogebra approach) and control group (traditional method). Based on Main-Whitney U-test, the experimental group performed better than the control group in the post-test analysis. Hence, there was a significant difference among the groups in the achievement test. The study concluded that Geogebra can increase students' interest, confidence, and motivation in learning Mathematics. It also concluded that teaching and learning of mathematics should not only focus on theory but should also include integrating software like Geogebra to stimulate interest in learning mathematics.

In another study by Shadaan and Leong (2013) whose purpose was to investigate students understanding in learning circles using Geogebra used a sample of 53 students. The sample consisted of 28 students for the experimental group and 25 students for the control group with the quasi-experimental design of two intact classes. The findings showed significant differences in scores of means in conceptual understanding of circles in favor of the experimental group who underwent the treatment with Geogebra. The results revealed that students had a positive attitude towards Geogebra. In conclusion, the study revealed that Geogebra can be used as an enabler in teaching and learning Mathematics, which has the tendency of creating a vibrant, cooperative, and collaborative learning environment.

A study conducted by Hutkemri and Effandi's (2012) used a sample of 284 students consisting of 138 in the experimental group (use of Geogebra) and 146 in the control group (without Geogebra use) that examined gender issues on procedural knowledge and conceptual abilities of functions. Their study used a quasi-experimental design by employing a non-equivalent pre-test and post-test control group design. Both pretest and posttest items were the same and these tests used pencil and paper without Geogebra. The finding revealed that male and female students' achievement in functions is the same after using Geogebra as an intervention. There was no significant difference in their mean scores. The assumption was that both genders received the same treatments hence equal experience level after the intervention. They suggested that Geogebra affects students' conceptual and procedural knowledge. Hence, Geogebra should be considered as a teaching and learning tool.

Bhagat and Chang (2015) whose purpose was to examine the impact of using Geogebra on 9th-grade students in learning circles by achievement test used a quasi-experiment research design of 25 students each for the experimental and control groups. The researcher taught both groups using Geogebra on the experimental group and the traditional method on the control group. The results favored the experimental group in a mean difference in the scores of the posttest. Hence, there was a significant difference between the experimental and control groups.

According to Rohaidah, Ting, Mor'ain, Zamzana, and Raja (2016), their study examined the effects of teaching circles with Geogebra. The quasi-experimental of nonequivalent pretest-posttest control group design was used to conduct the study. The total sample used was 46 , of which the control group had 17 students while the experiment group had 29 students. Their study adopted an attitude questionnaire of 22 items with options from strongly disagree to strongly agree. The findings indicated that there was no significant difference between the two groups in means. But the experimental group showed positive attitudes in using Geogebra in learning circles.

In summary, the majority of all the reviewed literature attests to the effectiveness of the software used to measure students' attitudes and academic achievements. The outcomes from the reviews are what the researcher wants to claim or reject. The recommendation for this study will depend on the availability of the results generated.

\section{- Geogebra Software}

Markus Hohenwater was the one who developed the Geogebra software in 2001 as part of his master's thesis at the University of Salzburg, Austria. Geogebra software is widely used in teaching all topics in mathematics from the basic level to the tertiary level. The software incorporates geometry, algebra, calculus into a single package. The software makes use of older software features like Maple, Derive, Cabri, and Geometer sketchpad, (Sahaa, Ayub \& Tarmizi, 2010). Geogebra has downloadable tutorials, pdf format manual online, and various step by step video on www.youtube.com, Shadaan, and Leong (2013). The software is available in 45 different languages and currently being used in 190 countries, with about 500,000 users a month. The software is innovative, open-source, free online, and can be downloaded at www.Geogebra.com. One good feature about Geogebra is that it combines CAS and DGS into single software (Hohenwarter \& Fuch, 2004). CAS helps in providing visualization capabilities while the DGS also helps in providing changeability ( $\mathrm{Lu}, 2008)$. The algebra and geometry windows enable visualization of points on function graphs, parameters changing as a result of slider usage. Geogebra is an easy and most convenient way of displaying charts and graphs of functions. With Geogebra, shapes can be dragged around, expanded, collapsed, and rotated on the screen both clockwise and anti-clockwise. The colors for background, lines, and curves help in emphasizing mathematics concepts by dragging points and lines. Other software like Mathematica and Maple requires programming and coding skills but Geogebra does not require such skills. It is easy to deal with because it is compatible with several operating systems. Geogebra window is shown below in figure 1 . 


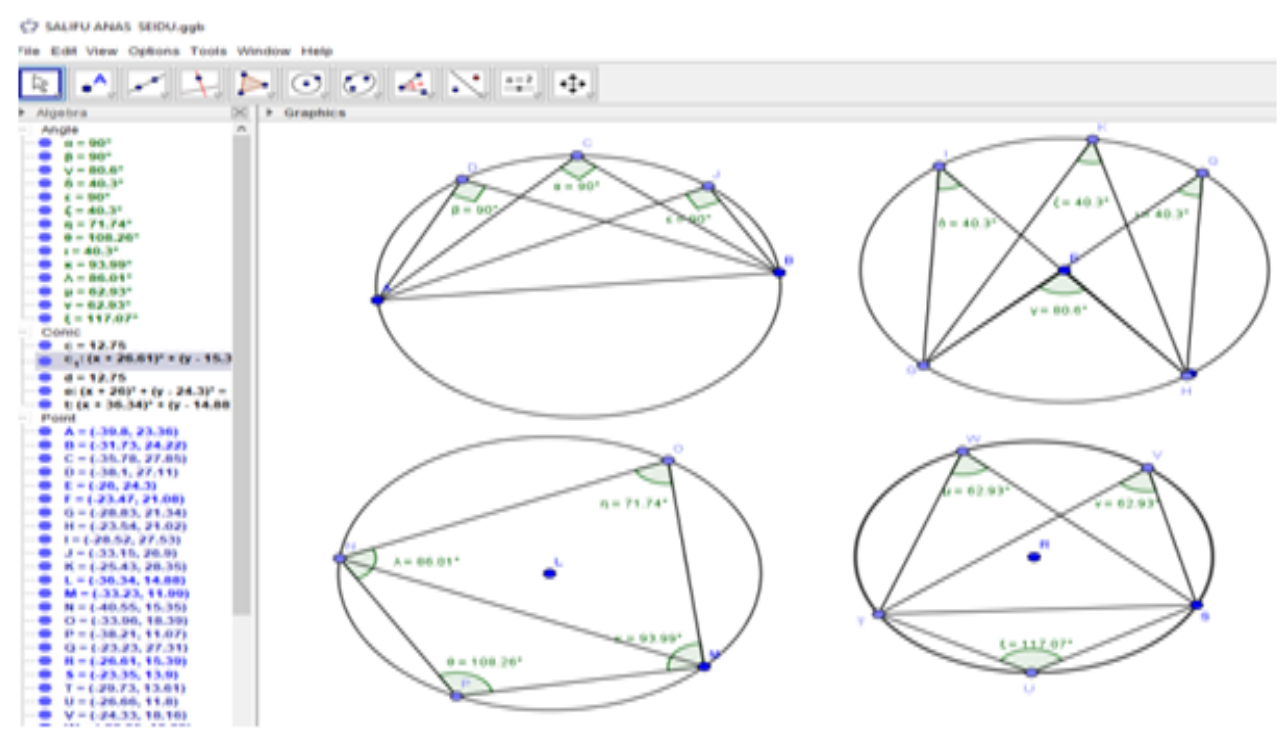

Fig 1:- Showing Geogebra window

The teaching of Geometry at the Colleges of Education Level in Ghana

In the Colleges of Education in Ghana, pre-service teachers are supposed to learn the following geometry topics in level 100 second semester and write semester exam, pass it before they obtain their Diploma in Basic Education Certificate. According to the draft syllabus of 2014, the topics are lines and angles, Geometrical construction, circles, polygons, measurement of 2-D, and 3$\mathrm{D}$ shapes. The rests are movement geometry and coordinate geometry. The geometry course objectives for the preservice teachers are as follows: the student will be able to: (1) Review and consolidate the concepts and skills related to Geometry. (2) Discover relations involving shapes, perimeters, areas, and volumes and use these to solve problems. (3) Relate and apply mathematical knowledge to solve problems in Geometry. The detailed geometry topics for the pre-service teachers in Ghana are as follows: (1) Lines and angles, Polygons, (2) Geometrical construction including loci, (3)Circles and Circle theorems, (4) 2Dimensional and 3-Dimensional shapes, and (5) Movement Geometry(Institute of education-UCC, Draft syllabus of 2014).
Theoretical Framework: Constructivist teaching and learning Approach with Geogebra

Shadaan and $\mathrm{Eu}$ (2013) posit that the Geogebra teaching approach supports constructivist views of teaching which ensures inquiry and direct hands-on, learners' autonomy, minds-on activities, social interaction, and sharing of ideas and opinions. Also, Dikovic (2009) indicates that Geogebra's advantages include: (1) helping learners and teachers to learn or do investigation in mathematics (2) Assist learners to acquire or gain knowledge themselves instead of being transmitted to by their teachers (3) boosts the interactive process of conjecture, feedback and collaboration among learners (4) ensure cooperative learning among learners (5) helping learners do demonstration and visualization through different representations and perspectives. Similarly, Geogebra has tremendous potential to influence the teaching of mathematics. This was also confirmed by Karadag and McDougall (2009) in their study that Geogebra users can utilize Geogebra in order to elucidate, discover and model mathematical concepts and interactions between mathematical concepts or mathematics as a whole.

\section{Conceptual Framework}

The conceptual framework for this study is given in Figure 2

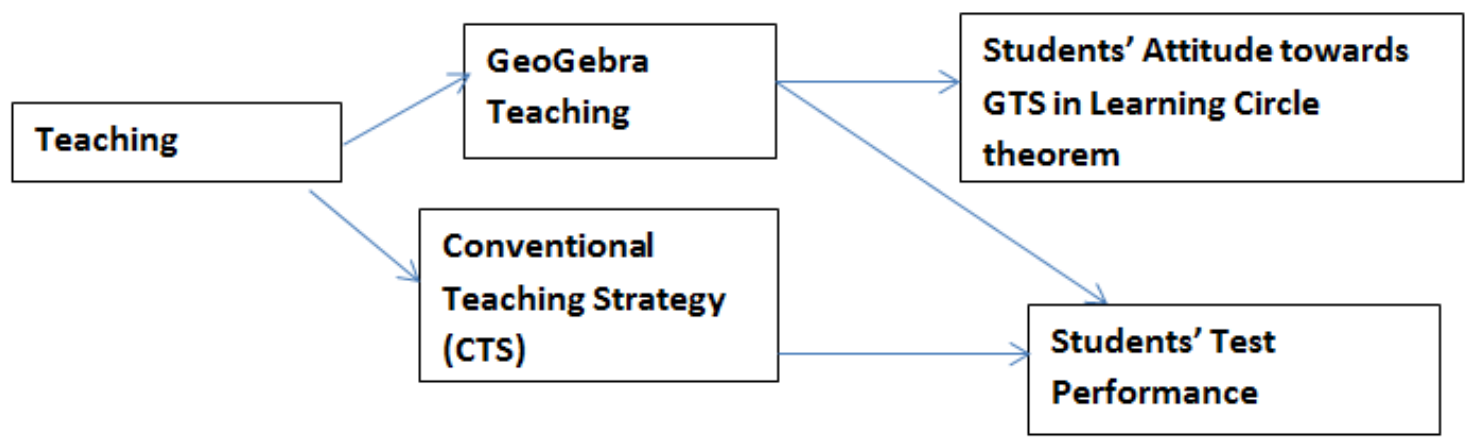

Fig 2:- The conceptual framework for this study 


\section{METHODOLOGY}

\section{$>$ Design of the study}

This study used a quasi-experimental research design with precisely the Before-After research design. The design used pretest-posttest design with a pure quantitative approach in data collection and analysis. The subjects were randomly selected for the groups. The summarized design is shown below in figure 3 .

\begin{tabular}{|c|c|c|c|}
\hline Groups & Pre - test & Treatment & Post - test \\
\hline $\begin{array}{c}\text { Geogebra teaching } \\
\text { strategy }\end{array}$ & $0_{1}$ & $\mathrm{X}$ & $0_{2}$ \\
\hline $\begin{array}{c}\text { Conventional teaching } \\
\text { strategy }\end{array}$ & $0_{1}$ & & $0_{2}$ \\
\hline
\end{tabular}

$0_{1}=$ pretest $\quad \mathrm{X}=$ treatment with Geogebra

$\mathrm{O}_{2}=$ posttest

Fig 3:- Quasi-Experimental Research Design

\section{> Population, Sample and Sampling Procedure}

The population was all general programme and science pre-service teachers comprising of levels 100, 200, and 300 of E.P. College of Education, Bimbilla- Ghana which was 1,190. Of these, 326 were Science Students and 864 were General program Students. A sample of 88 PreService Teachers was used with an average age of 23. They were uniformly grouped into the six classes based on their entry requirement from the Senior High School examinations by the college administration. The 88 preservice teachers were randomly selected from the six (6) classes to form the control and experimental groups. The two groups were again randomly assigned as control and experimental groups. The control group had a sample of 45 (male $=26$, female $=19)$ while the experimental group had 43 (male $=24$, female $=19)$. According to Gall, Gall \& Borg's (2003) study, an experimental research should have at least 15 subjects each in the control and experimental groups. Thus, the sample size in conducting this research for both groups is appropriate.

\section{$>$ Instrumentation and Pilot Study}

This study used both achievement test and a closeended questionnaire. The 15 multiple-choice achievement test questions were picked from "PowerPoint Series", a core mathematics textbook printed in Ghana for West African Senior High Schools pages 427-446 for the study. The multiple-choice questions were scored 2 marks each. So a maximum mark to be achieved was 30 . A survey questionnaire was adapted from Leong's (2013) study which was used to measure students' perceptions of sketchpad in Malaysia, after a reply to the researcher's request to use his questionnaire. However, it was modified based on the research questions to measure Pre-Service Teachers' perceptions of Geogebra in Ghana. The questionnaire was a 13 item questions measuring perceptions of Pre-Service Teachers' (i) usage of Geogebra on circles, (ii) how Geogebra helps in the understanding of circle theorem and (iii) on self-confidence in solving problem and abilities to communicate using Geogebra. Both the pretest and post-test lasted 1 hour while the questionnaire lasted for 20 minutes. The questionnaire used a Likert-scale of strongly agree-5, agree-4, neutral-3, disagree-2, and strongly disagree-1. The pilot study was conducted in the college to 30 pre-service teachers who were on field practicum and who were not part of the main study.

\section{Validity and Reliability}

The items of the test were based on the Colleges of Education, Ghana syllabi for level 100 second semester on circle theorem. The questions were reviewed by two experienced Mathematics Tutors of the College to crosscheck the content validity. They consulted the Colleges of Education Geometry course outlines and compared it to the test items in order to come out with recommendations on both face and content validation of the instrument. The tutors recommended that it met the pre-service teachers' standard. To calculate the reliability of the instruments, the Kuder-Richardson formula 20 method was adopted and used which gave reliability coefficient 0.75 . The reliability coefficient value of 0.75 implies that $75.0 \%$ of the variability in scores is due to true score differences among the pre-service teachers while the remaining $25.0 \%$ is due to measurement error. Nunnally, (1978) claimed that 0.7 and above reliability coefficient is acceptable. The 13 items closed questions were also validated by the same experts and the internal consistency reliability analysis resulted in a Cronbach's alpha coefficient of 0.83 which is high and good for administering.

\section{$>$ Independent and Dependent Variables}

The Geogebra Teaching Strategy and Conventional Teaching Strategy are the independent variables. The preservice teachers' achievement on circle theorem test and their perception towards Geogebra Teaching Strategy on circle theorem are considered as dependent variables.

\section{$>$ Procedure and Data Collection}

This study consisted of 3 phases.

1st Phase: The pretest was conducted on 17th March, 2014, a week before the intervention exercise. The control and the experimental group took the 15 questions pretest on circles, the time allowed was 1 hour. Three questions each were drawn from the following theorems to constitute the pretest:

- Angles subtended from a diameter at the circumference are $90^{\circ}$.

- Angles in the opposite segment of a circle add up to $180^{\circ}$.

- Angle which subtends at the center is twice angled which subtends at any point on the circumference.

- Angles from the same segment of a circle are equal.

- Tangent angles which require the use of alternate principles.

2nd Phase: The control group attended regular classes based on the timetable of the College, while the experimental group had evening lessons twice a week for 3 weeks from 24th March 2014 to 11th April 2014. Each lesson session lasted two hours. Both groups were taught by the same tutor. The control group received direct 
lectures from the teacher by listening, observing, and working questions directly from their handouts and textbooks. The experimental group, using the Geogebra software, constructed diagrams, worked examples based on their textbooks too. Experimental group was given written instructions to learn circles by exploring, investigating, conjecturing, and visualizing circle theorem properties. The circles theorem sub-topics both groups undertook are Parts of a circle; properties of chords; circle theorems, and tangents.

The questionnaire was administered to the experimental group to measure their perception towards the treatment of circle theorems. The experimental group filled the perception questionnaire before the posttest to eliminate possible influence that might arise from the posttest. The perception questionnaire was grouped into three subheadings as (i) usage of Geogebra, (ii) how Geogebra helps in the understanding of circle theorem, and (iii) on self-confidence in solving problems and abilities to communicate using Geogebra.

3rd Phase: The Fifteen (15) questions post-test was taken by both groups on circles theorems which were paper and pencil activities without computer usage on 11th April 2014. The detailed posttest circle theorems questions were drawn from the following theorem:

- Six of the achievement test questions were on an angle that subtends at the center is twice which subtends at any point on the circumference.

- Two of the questions were also on angles in the opposite segment of a circle add up to $180^{\circ}$.

- Two questions were also from angles subtended from a diameter at the circumference is $90^{\circ}$.

- Three questions were also from the theorem that states that angles from the same segment of a circle are equal.

- Two questions were from tangent which required the use of alternate principles.

\section{$>$ Control Group Lesson Delivery}

- Week 1: Objectives

be able to:

By the end of the week Pre-service teachers would

$\checkmark$ Identify the various parts of a circle.

$\checkmark$ Establish that in a circle the angles in the same segment are equal by measuring using a protractor.

$\checkmark$ Show that the angle subtended at the center of a circle by an arc is twice the angle it subtends at the circumference by measuring using a protractor.

$\checkmark$ Show that angle subtended by diameter at the circumference is a right angle by measuring using a protractor.

\section{- Week 2: Objectives}

By the end of the week Pre-service teachers would be able to:

$\checkmark$ Show that sum of opposite angles in a cyclic quadrilateral equal's $180^{\circ}$ by measuring using a protractor.
Show that angles which chord makes with the tangent are equal to the angles in the alternate segments by measuring using a protractor.

- Week 3: Objectives

By the end of the week Pre-service teachers would be able to:

$\checkmark$ Use all the circle theorems to solve circle problems.

$\checkmark$ Write posttest on circles theorem.

\section{Experimental Group Lesson Delivery}

- Week1: Objectives

By the end of the week Pre-service teachers would be able to:

$\checkmark$ To open Geogebra software on the desktop.

$\checkmark$ Explore the GeoGebra windows and all the tools like moving tools, circle tools, line tools, point tools, construction tools, etc.

$\checkmark$ Explore the functions of some of the tools to be used in the teaching of circles.

$\checkmark$ Experiment with some tools by constructing points, angles, and labeling them.

$\checkmark$ Drag points and move points and shapes around and apart and visualize.

- Week 2: Objectives able to:

By the end of the week pre-service teachers would be

$\checkmark$ Construct angles by using the angle tools and labeling using the labeling tools.

$\checkmark$ Measure acute, obtuse, and reflex angles by using the angle measurement tools by measuring both anticlockwise and clockwise directions.

$\checkmark$ Construct different circles.

1. Construct different circles with several specific radii.

2. Construct different circles without radii.

$\checkmark$ Construct several circles with the theorem which states that angles subtending from the center of the circle is twice the angle of any point on the circumference and measure the angles using Geogebra measuring tool.

$\checkmark$ Construct several circles with the theorem that, the sum of angles a chord subtends at the circumference of an opposite segment of a circle is $180^{\circ}$ and measure the angles using the Geogebra measuring tool.

$\checkmark$ Construct several circles with the theorem that angles subtended by diameter at the circumference is a right angle and measure the angles using the Geogebra measuring tool.

\section{- Week3: Objectives} able to:

By the end of the week Pre-service teachers would be

$\checkmark$ construct several circles with the theorem that, angles subtended by the same chord, anywhere in the same segment of the circle are equal and measure the angles using Geogebra measuring tool. 
$\checkmark$ Construct several circles with the theorem that, the opposite angles of a cyclic quadrilateral are supplementary and measure the angles using the Geogebra measuring tool.

$\checkmark$ Construct several circles with the theorem that, angles between a tangent to a circle and a chord through the

Some intervention activities by the experimental Group

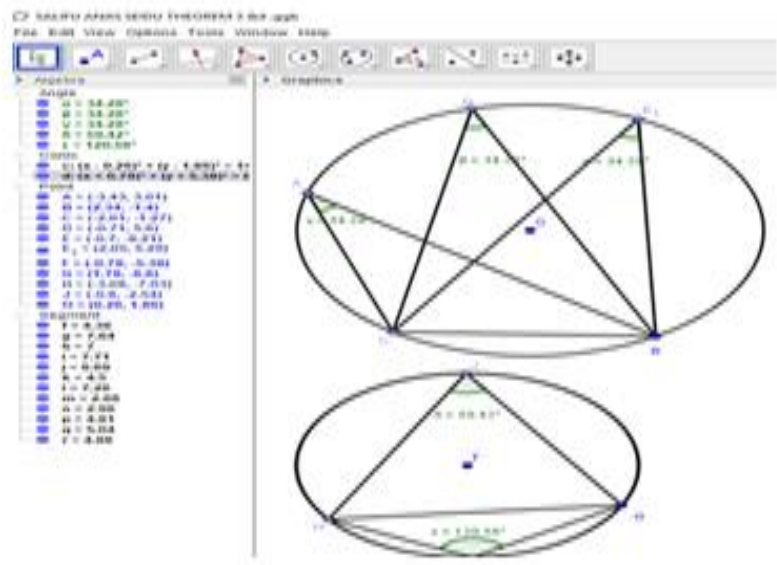

Fig 4:- Two windows showing Geogebra activities on circle theorems during the intervention

\section{Data Analysis}

The achievement test scores of pretest and posttest data were analyzed using the independent and paired samples t-tests at the 0.05 significance level. SPSS Version 18 was used to test for statistical significance differences between the means and standard deviations of pretest and posttest. Cohen's "d" effect size was also calculated to ascertain the level of the impact of the intervention. The perception questionnaire was analyzed using descriptive statistics (mean, standard deviation, and percentages of each item) generated from the SPSS to answer the research question. For the purpose of the analyses, the Likert scale was collapsed into disagree, neutral, and agree.

\section{RESULTS}

The results in the study are presented according to research questions as follows:

Research Question 1: Is there a significant difference in pre-test achievement between the control group and the experimental group?

\begin{tabular}{|c|c|c|c|c|c|c|}
\hline Group & N & Mean & $\begin{array}{c}\text { Std. } \\
\text { Dev. }\end{array}$ & Df & t & Significance \\
\hline Control Group & 45 & 18.3 & 4.06 & 86 & 0.685 & 0.495 \\
\cline { 1 - 3 } $\begin{array}{c}\text { Experimental } \\
\text { Group }\end{array}$ & 43 & 17.7 & 2.99 & & & \\
\hline
\end{tabular}

Table 1:- Independent sample t-test of pre-test scores of Control and Experimental Groups

From Table 1, the pretest mean scores of the control group $(\mathrm{M}=18.3, \mathrm{SD}=4.06)$ and the experimental group of $(\mathrm{M}=17.7, \mathrm{SD}=2.99)$ were compared using independent point of contact is equal to the angle in the alternate segments and measure the angles using Geogebra measuring tool.

$\checkmark$ Fill the perception questionnaires and write posttest on circles theorem.

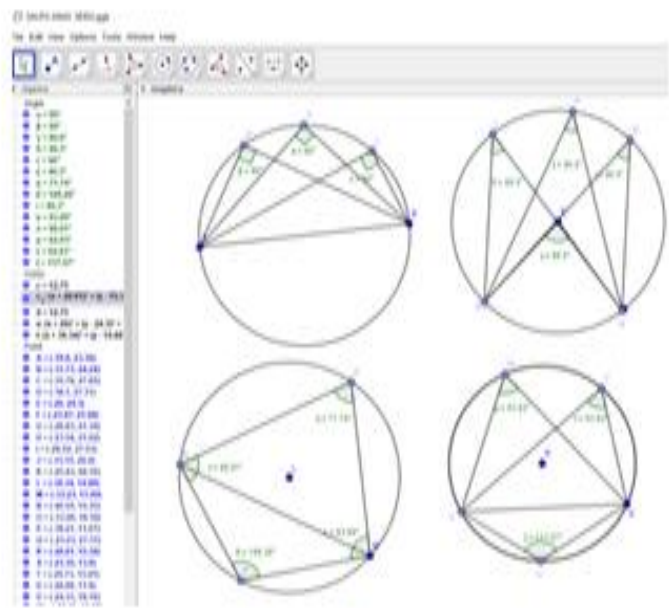

sample t-test. The result of the t-test was $t(86)=0.685, p=$ 0.495 . Also, majority of the control group PSTs scores fell within the range of $(14.24-22.3)$ while the majority of the experimental group scores also fell within the range of (14.71 - 20.69). Since the p-value of 0.495 exceeds the significant level of 0.05 , it can be concluded that there was no significant difference in pretest scores of both groups. Hence the null hypothesis is upheld. This suggests that preservice teachers were at the same level of thinking on circle theorem before the use of treatment with Geogebra.

Research Question 2: Is there any significant effect of the Geogebra Teaching Strategy on pre-service teachers' understanding of circle theorems when compared with the conventional approach in the posttest?

\begin{tabular}{|c|c|c|c|c|c|c|}
\hline Group & N & Mean & Std. Dev. & Df & t & Significance \\
\hline Control Group & 45 & 20.7 & 1.95 & 86 & -17.24 & 0.000 \\
\cline { 1 - 4 } $\begin{array}{c}\text { Experimental } \\
\text { Group }\end{array}$ & 43 & 27.6 & 1.79 & & & \\
\hline
\end{tabular}

Table 2:- Independent sample t-test of post-test scores of Control and Experimental Groups

After the treatments, the comparison of the posttest mean scores of the control group $(M=20.7, S D=1.95)$ and the experimental group $(M=27.6, S D=1.79)$ revealed statistically significant difference in favor of the experimental group since $(\mathrm{t}(86)=-17.24, \mathrm{p}=0.00<0.05)$. The mean difference between the groups in the posttest is 6.9.This implies majority of the control group PSTs scores fell within the range of (18.75 -22.65) while the majority of 
the experimental group scores also fell within the range of $(25.81$ - 29.39). The result shows that the pre-service teachers who used Geogebra to learn circle theorems did better than those who were taught with the traditional approach. Hence, the null hypothesis is rejected. The effect size of the Geogebra treatment was calculated to determine the extent of the intervention. The effect size Cohen's d = 3.69 which is large effect size was realized. Detailed calculation is shown below. This effect size value implies that the Geogebra teaching approach has made a tremendous impact on pre-service teachers' concepts of circles theorems.

Cohen's d $=\frac{M_{2-} M_{1}}{\sqrt{\frac{\left(N_{1-1}\right) \times S D_{1}{ }^{2}+\left(N_{2-1}\right) \times S D_{2}{ }^{2}}{N_{1}+N_{2}-2}}}, \mathrm{~d}=\frac{27.6-20.7}{\sqrt{\frac{44(1.95)^{2}+42(1.79)^{2}}{43+45-2}}}$
$, \mathrm{~d}=\frac{6.9}{\sqrt{\frac{167.31+134.57}{86}}}, \quad \mathrm{~d}=\frac{6.9}{1.87}, \quad \mathrm{~d}=3.69$

Where $\mathrm{M}_{1}, \mathrm{M}_{2}, \mathrm{SD}_{1}$, and $\mathrm{SD}_{2}$ are the means and standard deviations of the groups. Also, $\mathrm{N}_{1}, \mathrm{~N}_{2}, \mathrm{SD}_{1}{ }^{2}$, and $\mathrm{SD}_{2}{ }^{2}$ are the sample size and variance of the groups.

Further analysis to determine the extent of improvement of performance before and after the treatments was conducted using paired sample t-test. Table 3 displays the result of the analysis.

\begin{tabular}{|c|c|c|c|c|c|c|}
\hline & Group & $\begin{array}{c}\text { Mean } \\
\text { Difference }\end{array}$ & S.D & df & t & Sig.(2-tailed) \\
\hline Pair 1 & $\begin{array}{c}\text { Experimental } \\
\text { (Posttest-pretest) }\end{array}$ & 9.8 & 3.58 & 42 & 18.03 & 0.000 \\
\hline Pair 2 & $\begin{array}{c}\text { Control } \\
\text { (Posttest-pretest) }\end{array}$ & 2.4 & 2.82 & 44 & 5.75 & 0.000 \\
\hline
\end{tabular}

Table 3:- Paired sample t-test of pretest and posttest of Experimental and control groups

A paired-samples t-test was used to examine preservice teachers' achievement before and after treatments. As illustrated in Table 3, the mean difference between the posttest and the pretest of the control group was 2.4 with t- value of 5.75 and $p$-value of 0.00 . The p-value is lower than 0.05 , indicating that the difference between the pretest and post-test scores of the control group was significant.

For the experimental group, the mean difference between the posttest and the pretest was 9.8 and a t-value of 18.03 with a p-value of 0.000 was noticed. Since the pvalue is lower than 0.05 , it can be concluded that there was a significant difference between the pretest and posttest scores of the experimental group. The effect size of the Geogebra treatment was calculated to determine the extent of the intervention. The effect size Cohen's $d=2.75$ which is large effect size was noted. The detailed calculation is shown below.

$\mathrm{d}=\frac{t \text {-value }}{\sqrt{n}}, \quad \mathrm{~d}=\frac{18.03}{\sqrt{43}}=\frac{18.03}{6.56}=2.75$. Where $\mathrm{n}$ is the sample size of the experimental group.

This large effect size value signifies that the Geogebra approach made a great impact on pre-service teachers' acquisition of circle theorem concepts. Careful analysis of the independent t-tests and the paired sampled t-test indicates that even though both groups gained significantly from the approaches, the Geogebra teaching strategy proved superior.

\section{Research Question 3: What are pre-service teachers' perceptions about the use of Geogebra in learning circles?}

The questionnaire used to collect data on pre-service teachers' perception of Geogebra teaching strategy was in three parts as follows: (i) Geogebra usage,(ii) understanding circle theorem by Geogebra, and (iii) selfconfidence and ability to solve circle problems using Geogebra. Table 4 displays the result of the analysis of the Geogebra usage by the pre-service teachers. For the purpose of the analysis, the Likert scale was collapsed into disagree, neutral, and agree.

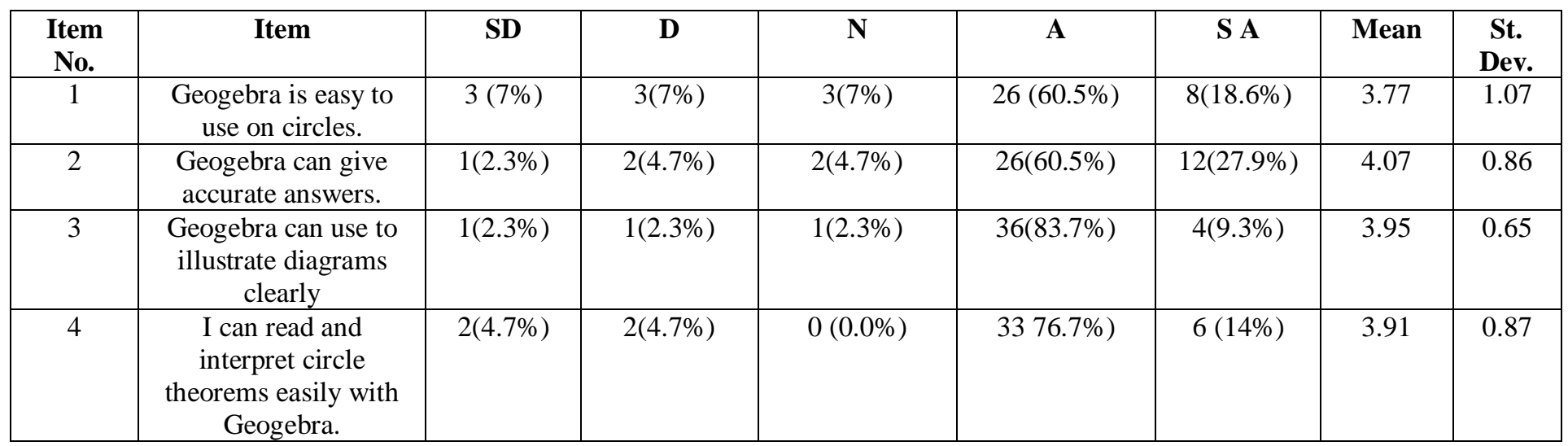

Table 4:- Pre-Service Teachers usage of Geogebra perceptions on percentage, frequency, mean, and standard deviation.

From Table $4,79 \%$ of the pre-service teachers agreed that, Geogebra is easy to use to explore circle theorems, $14 \%$ disagreed and $7 \%$ stayed neutral. The mean and standard deviation of the responses on this item is 3.77 and
1.07 respectively. Approximately, $88.4 \%$ of the pre-service teachers agreed that Geogebra gives accurate answers, $7 \%$ disagreed and $4.7 \%$ were undecided. A mean of 4.07 was recorded with standard deviation of 0.86 . On whether 
Geogebra can help illustrate diagrams of angles clearly, majority of $93 \%$ answered in favor, $4.6 \%$ disagreed and $2.3 \%$ remained undecided. The mean and standard deviation of the responses on this item was 3.95 and 0.65 respectively. On the response of the pre-service teachers on interpreting circle theorem diagrams easily with Geogebra $90.7 \%$ agreed, 9.4\% disagreed with none undecided. It resulted in a mean of 3.91 with a standard deviation of 0.87 .
In general, the study found that item 1, which stated that "Geogebra is easy to use on circles" in the questionnaire had the least mean of 3.8 while item 2 which was "Geogebra can give accurate answers" produced the highest mean of 4.1. The overall mean and standard deviation of pre-service teachers' usage of Geogebra are 3.93 and 0.86 respectively. It can be concluded that preservice teachers who used Geogebra to learn circle theorems perceived it positively. The next part was based on whether Geogebra helped them in understanding circle theorems.

\begin{tabular}{|c|c|c|c|c|c|c|c|c|}
\hline $\begin{array}{l}\text { Item } \\
\text { No. }\end{array}$ & Item & $\begin{array}{l}\text { Strongly } \\
\text { Disagree }\end{array}$ & Disagree & Neutral & Agree & $\begin{array}{c}\text { Strongly } \\
\text { Agree }\end{array}$ & Mean & $\begin{array}{l}\text { Standard } \\
\text { Deviation }\end{array}$ \\
\hline 5 & $\begin{array}{l}\text { Geogebra helps me to } \\
\text { get greater in- depth on } \\
\text { circle theorems }\end{array}$ & $8(18.6 \%)$ & $10(23.3 \%)$ & $3(7 \%)$ & $22(51.2 \%)$ & $0(0 \%)$ & 2.91 & 1.23 \\
\hline 6 & $\begin{array}{l}\text { Geogebra helps me } \\
\text { understand circles } \\
\text { theorem easily. }\end{array}$ & $3(7 \%)$ & $6(14 \%)$ & $8(18.6 \%)$ & $22(51.2 \%)$ & $4(9.3 \%)$ & 3.42 & 1.07 \\
\hline 7 & $\begin{array}{l}\text { I understand lessons } \\
\text { better with Geogebra } \\
\text { than the conventional } \\
\text { method. }\end{array}$ & $4(9.3 \%)$ & $7(16.3 \%)$ & $2(4.7 \%)$ & $27(62.8 \%)$ & $3(7 \%)$ & 3.42 & 1.14 \\
\hline 8 & $\begin{array}{c}\text { Geogebra allows } \\
\text { dynamic investigation } \\
\text { of circles theorems } \\
\text { properties }\end{array}$ & $1(2.3 \%)$ & $2(4.7 \%)$ & $1(2.3 \%)$ & $30(69.8 \%)$ & $9(20.9 \%)$ & 4.02 & 0.80 \\
\hline 9 & $\begin{array}{l}\text { When I change angles in } \\
\text { circles theorem I see } \\
\text { changes in the new } \\
\text { angles. }\end{array}$ & $0(2.32 \%)$ & $0(2.32 \%)$ & $0(0.00 \%)$ & $29(67.4 \%)$ & $14(32.6 \%)$ & 4.33 & 0.47 \\
\hline
\end{tabular}

Table 5:- Pre-Service Teachers perception on how Geogebra helps the understanding of circle theorem, frequency and percentage.

From Table 5, the majority of the pre-service teachers representing $51.2 \%$ agreed, $41.9 \%$ disagreed and $7 \%$ remained undecided that Geogebra helped them to get greater in-depth knowledge on circle theorems. A mean score of 2.91 and a standard deviation of 1.23 were recorded. The majority representing $60.5 \%$ of the preservice teachers agreed to the assertion that Geogebra helped them to understand circles theorem easily. Twentyone percent $(21 \%)$ disagreed with the claim and $18.6 \%$ preservice teachers stayed neutral. A mean of 3.42 and a standard deviation of 1.07 respectively were recorded.

On whether pre-service teachers understood the lessons better when using Geogebra compared to the conventional methods, $69.8 \%$ of them agreed, $25.6 \%$ disagreed and $4.7 \%$ indicated neutral. The mean and standard deviation were 3.42 and 1.14 respectively. Approximately, $91 \%$ of the pre-service teachers agreed that
Geogebra allowed more investigation of circle theorems, $7 \%$ disagreed, and $2.3 \%$ were undecided. A mean of 4.02 and a standard deviation of 0.80 were recorded. All preservice teachers agreed that they could see the shape of the angles changing when dragging points. A mean of 4.33 and a standard deviation of 0.47 were recorded.

In conclusion, the study found that the item 5 which stated that "Geogebra helps me to get greater in-depth on circle theorems" in the questionnaire, had the least mean of 2.91 while item 9 which stated that "When I change angles in circles theorem I see changes in the new angles", produced the highest mean 4.33 . The overall mean and standard deviation of pre-service teachers on "how Geogebra helped them understand circle theorem" were 3.62 and 0.94 respectively. It can be concluded that preservice teachers have positive perceptions towards Geogebra and it helped them to understand circle theorem. 
ISSN No:-2456-2165

\begin{tabular}{|c|c|c|c|c|c|c|c|c|}
\hline $\begin{array}{c}\text { Item } \\
\text { No. }\end{array}$ & Item & $\begin{array}{c}\text { Strongly } \\
\text { Disagree }\end{array}$ & Disagree & Neutral & Agree & $\begin{array}{c}\text { Strongly } \\
\text { Agree }\end{array}$ & Mean & $\begin{array}{c}\text { Standard } \\
\text { Deviation }\end{array}$ \\
\hline 10 & $\begin{array}{c}\text { I am more confident in } \\
\text { solving problems with } \\
\text { Geogebra on circles } \\
\text { theorem. }\end{array}$ & $6(14 \%)$ & $9(20.9 \%)$ & $2(4.7 \%)$ & $18(41.9 \%)$ & $8(18.6 \%)$ & 3.30 & 1.37 \\
\hline 11 & $\begin{array}{c}\text { I dare investigate more } \\
\text { difficult problems and } \\
\text { solve them. }\end{array}$ & $6(14 \%)$ & $6(14 \%)$ & $5(11.6 \%)$ & $18(41.9 \%)$ & $8(18.6 \%)$ & 3.37 & 1.33 \\
\hline 12 & $\begin{array}{c}\text { Geogebra helps me in the } \\
\text { classroom discussion. }\end{array}$ & $3(7 \%)$ & $5(11.6 \%)$ & $5(11.6 \%)$ & $25(58.1 \%)$ & $5(11.6 \%)$ & 3.60 & 1.08 \\
\hline 13 & $\begin{array}{c}\text { The software assists me to } \\
\text { interact with both } \\
\text { colleagues and teachers. }\end{array}$ & $9(20.9 \%)$ & $5(11.6 \%)$ & $0(0 \%)$ & $27(62.8 \%)$ & $2(4.7 \%)$ & 3.19 & 1.33 \\
\hline
\end{tabular}

Table 6:- Pre-Service Teachers' perception on self-confidence in solving problems and abilities to communicate using Geogebra (frequency and percentage).

Table 6 summarizes the pre-service teachers' selfconfidence and ability to solve circle problems using Geogebra. For item 10, 60.5\% indicated that they have the needed self-confidence in solving problems on circle theorem using Geogebra while $34.9 \%$ disagreed and $4.7 \%$ indicated neutral. The mean and standard deviation for the item were 3.30 and 1.37 respectively. The majority of the pre-service teachers representing $60.5 \%$ were ready to investigate difficult problems on circle theorem, while $28 \%$ were not ready and yet $11.6 \%$ stayed undecided. The mean and standard deviation of that response were 3.37 and 1.33 respectively. About $70 \%$ of pre-service teachers indicated that Geogebra helped them to engage with their peers and the teacher while $18.6 \%$ disagreed, with $11.6 \%$ undecided. It recorded a mean of 3.60 and a standard deviation of 1.08 . For item 13, there was no response for neural but, $67.5 \%$ agreed that Geogebra encouraged them to interact with the teachers and peers in the classroom while $32.5 \%$ disagreed. The mean was 3.19 with a standard deviation of 1.33 which is a positive result. In general, the study found that "the software assists me to interact with both colleagues and teachers" had the least mean of 3.19 while "Geogebra helped me in the classroom discussion" produced the highest mean 3.60. The overall mean and standard deviation of pre-service teachers' self-confidence in solving problems and abilities to communicate using Geogebra were 3.37 and 1.28 respectively. It can be concluded that pre-service teachers have positive perceptions towards Geogebra on self-confidence in solving problems and abilities to communicate.

\section{$>$ Discussion of Results}

For this study, Geogebra was used as the teaching and learning tool. It was also used as an independent variable to examine its effects on students' performance and their perceptions.

\section{The achievement test}

The results showed that there was a significant difference with the large effect size between the experimental group using Geogebra and the control group without the usage of the software. The usage of Geogebra has benefited the pre-service teachers since there was significant improvement in the posttest scores from their pretest scores. The experimental group pre-service teachers performed well in post-test because their wrong judgment in the pre-test was minimal in the post-test on (1) tangent angles which required the use of alternate principles (2) angle which subtends at the center is twice angled which subtends at any point on the circumference and (3)angles in the opposite segment of a circle add up to 1800. The results favored the experimental group when the independent t-test was employed to analyze the means. This finding is consistent with studies by (Noorbaizuru \& Leong, 2013; Bhagat \& Chang, 2015; Zengin et al, 2012; Sharifah \& Hutkemri, 2017; Nazihatulhasanah \& Nurbiha, 2015; Shadaan \& Leong, 2013; Pavethira \& Leong, 2017) which found significant gains in favor of students using Geogebra and geometer sketchpad. For instance, Noorbaizuru and Leong (2013) found a difference in the mean posttest of 4.00 in favor of the experimental group who used Geogebra to learn fractions. In terms of learning statistics, Emaikwu et al (2015), students who used Geogebra had gained higher than the control group in the posttest which tallies with this study. Similarly, Shadaan and Leong (2013), a mean difference of 4.22 was recorded on circles in favor of the Geogebra group which agrees with this study.

\section{> Perception Questionnaire}

In terms of usage of Geogebra, pre-service teachers showed positive attitudes towards Geogebra on circle theorems. They indicated that Geogebra is easy to use, gave them accurate answers, and enabled them to illustrate diagrams and interpret circle theorem clearly. Overall mean and standard deviation was 3.93 and 0.86 respectively.

Pre-service teachers also indicated that Geogebra helped them to get in-depth knowledge and understanding of circle theorem than the conventional methods. They also attested to the fact that Geogebra enabled them to do more dynamic investigation of circle theorem properties through visualization by dragging and movement of points and shapes. Overall mean and standard deviation was 3.62 and 0.94 respectively. 
The pre-service teachers finally indicated that they were confident in using Geogebra to do investigations on circle theorems through interaction and classroom discussions. Overall mean and standard deviation for the self-confidence in problem-solving and the ability to communicate using Geogebra are 3.37 and 1.28 respectively.

These findings are in line with finding by Nazihatulhasanah and Nurbiha (2015), who concluded that Geogebra enables students to gain positive perception towards learning. This is comprehensible with many other studies that reported increases in students' positive attitude, perceptions, and motivation in learning mathematics (Kamariah, et al 2010) and Harizon (2005). For example, Harizon (2005) reported that more than $80 \%$ of students displayed positive perceptions of Geometer's Sketchpad.

\section{CONCLUSIONS AND RECOMMENDATIONS}

The study concludes that there was a significant difference between the control and experimental groups in pre-service teachers' achievement in the circle theorem with a large effect size in the treatment using GeoGebra. The results showed that the experimental group using Geogebra performed better than the control group. Pre-service teachers also showed positive perceptions towards the use of Geogebra in learning circle theorem. The study found that pre-service teachers perceive the usage of Geogebra as significant in:

$>$ their performance in circle theorem,

$>$ helping them understand circle theorems and

$>$ improving their self-confidence in problem solving involving circle theorems

It is recommended that policymakers in Ghana's educational system should ensure teachers incorporate technology integration software like Geogebra into the teaching and learning of Circle theorems at the colleges of education. Future studies should be done on other geometry topics using Geogebra. In such studies, gender differences could be compared.

\section{REFERENCES}

[1]. Akayuure, P., Nabie, M. J., \& Sofo, S. (2013). Ghanaian Prospective Mathematics Teachers' Perceived Self-Efficacy towards Web Pedagogical Content Knowledge. International Journal of Liberal Arts and Social Science, 1(3), 132-140. ISSN: 2307924X, www.ijlass.org

[2]. Bhagat, K. K., \& Chang, C. Y. (2015). Incorporating Geogebra into geometry learning-A lesson from India. Eurasia Journal of Mathematics, Science and Technology Education, 11(1), 77-86. DOI: $\underline{10.12973 / \text { eurasia.2015.1307a }}$

[3]. Dogan, M. (2010). The role of dynamic geometry software in the process of learning: Geogebra example about triangles. Retrieved from: http://www.time2010.uma.es/Proceedings/Papers/A02 6_Paper.pdf
[4]. Emaikwu, S.O., Iji, C. O., \& Abari, M.T. (2015). Effect of Geogebra on Senior Secondary School Students interest and achievement in Statistics in Makurdi Local Government Area of Benue state, Nigeria. IOSR Journal of mathematics, 11(3), 14-21.

[5]. Gall, M. D., Borg, W. R., \& Gall, J. P. (2003).Education research: An introduction. (7th Edition). White plains, New York: Longman.

[6]. Hohenwarter, M., \& Fuchs, K. (2004). Combination of dynamic geometry, algebra and calculus in the software system Geogebra. Computer Algebra Systems and Dynamic Geometry Systems in Mathematics Teaching Conference.

[7]. Hohenwarter, M., \& Jones, K. (2007) Ways of linking geometry and algebra: the case of Geogebra. Proceedings of the British Society for Research into Learning Mathematics, 27 (3), 126-131.

[8]. Horizon, S. (2005). Persian Geometer's sketchpad sebagaibahaninterraktifdalam

pengajarandanpembelajaranmatematik:

kestangenkeepadabulatan. (Unpublished Masters dissertation). University Pendidikan Sultan Idris , Perak.

[9]. Hutkemri, Z., \& Effandi, Z. (2012).The Effect of Geogebra on Students'Conceptual and Procedural Knowledge of a Function, Indian Journal of Science and Technology, 5(1), 104-110.

[10]. Idris, N. (2006). Teaching and Learning of Mathematics: Making Sense and Developing Cognitives Ability. Kuala Lumpur: Utusan Publications \& Distributors Sdn. Bhd. InfoDev.(2010). ICT in School Education (Primary and Secondary).Retrieved from http://www.infodev.org/infodevfiles/resource/Infodev Documents_1016.pdf

[11]. Institute of Education (2014.) Revised draft syllabus for Three-Year Diploma in basic Education for fiveSemester Programme University of Cape Coast.

[12]. Institute of Education (2013). Professional board report on results analysis of geometry for $2^{\text {nd }}$ semester examination for diploma in basic education. Cape Coast: University of Cape Coast.

[13]. Institute of Education (2015). Professional board report on results analysis of geometry for 2 nd semester examination for diploma in basic education. Cape Coast: University of Cape Coast.

[14]. Kamariah, A. B,, Ahmad Fauzi, M.A., Wong, S.L., \& Rohani, A. T.(2010). Exploring secondary school students'motivation using technologies in teaching and learning mathematics. Procedia - Social and Behavioral Sciences 2, 4650-4654.

[15]. Leong, K. E. (2013). Impact of Geometer's Sketchpad on students achievement in graph functions. The Malaysian Online Journal of Educational Technology, 1(2), 19-31.

[16]. Lu, A.Y.W. (2008). English and Taiwaneses upper secondary teachers' approaches to the use of Geogebra. Acta Scientiae 10(2), 3855. 
[17]. Ministry of Education (2008).ICT in Education Policy, Republic of Ghana. http://www.moe.gov.gh/assets/media/docs/ICTinEduc ationpolicy_NOV2008.pdf

[18]. Nazihatulhasanah, A., \& Nurbiha, A. S. (2015). The effects of Geogebra on students Achievement. Procedia - Social and Behavioral Sciences, 172, 208 $-214$.

[19]. Noorbaizura, T., \& Leong, K. E. (2013). Effect of Students' Achievement in Fractions Using Geogebra. SAINSAB 16, 97-106.

[20]. Nunnally, J. C. (1978). Psychometric theory (2nd ed.). New York: McGraw-Hill.

[21]. Olkun, S., \& Aydogdu, T. (2003). Third international mathematics and science research (TIMMS): what is math? Neyisorgu on? Örnekgeometrisorulariveetkinlikare. Primary education-Online, 2(1), 28-35.

[22]. Pavethira, S., \& Leong, K. (2017). Students' Performance in Geometrical Reflection Using Geogebra. Malaysian Online Journal of Educational Technology, 5(1), 65-76.

[23]. Rohaidah, M., Ting, S.H., Nor'ainMohd, T., Zamzana, Z., \& Raja Lailatul, Z. M. (2016).The effects of using Geogebra Teaching strategy in Malaysian secondary schools: A case study from Sibu, Sarawak. Malaysian Journal of Society and Space 12(7), 13 - 25.
[24]. Royati, A., Ahmad, F., \& Rohani, A.T.(2010). The effects of Geogebra on Mathematics achievement: Enlightening coordinate geometry learning. ProcediaSocial and Behavioral Sciences 8: 686-693

[25]. Sahaa, R., Ayub, A., \& Tarmizi, R. (2010). The effects of Geogebra on Mathematics achievement: Enlightening coordinate geometry learning. Procedia Social and Behavioral Science, 8, 686-693.

[26]. Shadaan, P., \& Eu, L. K. (2013). Effectiveness of Using Geogebra on Students' Understanding in Learning Circles. The Malaysian Online Journal of Educational Technology, 1(4), 1-11.

[27]. Sharifah, N., \& Hutkemri, Z. (2017). The Effectiveness of the Geogebra Software: The Intermediary Role of Procedural Knowledge on Students' Conceptual Knowledge and Their Achievement in Mathematics. Eurasia Journal of Mathematics, Science \& Technology Education; 13 (6):2155-2180

DOI: https://doi.org/10.12973/eurasia.2017.01219a

[28]. William, C., Charles-Ogan, G., \& Adesope, R.Y. (2017).The Geogebra interactive software and senior secondary school Three (3) students interest and achievement in mathematics. International journal of mathematics and statistics studies, 5(1),1-8.

[29]. Zengin, Y., Furkan, H., \& Kutluca, T. (2012). The effect of dynamic mathematics Software Geogebra on student achievement in teaching of trigonometry. Procedia - Social and Behavioral Sciences, 31(0), 183-187

\section{APPENDIX}

Post Test on Circle Theorems $\quad$ Time: $\mathbf{3 p m}-\mathbf{4 p m} \quad 11^{\text {th }}$ April, 2014.

1. Find the value of $x$ in the figure below
(a) $35^{\circ}$
(b) $140^{\circ}$
(c) $110^{\circ}$
(d) $120^{\circ}$
(e) $290^{\circ}$

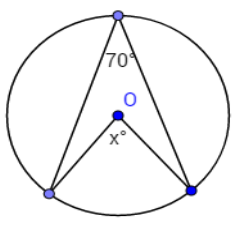

2. Find $x$ if $y=80$, in the figure below where $|A B|$ is the diameter
(a) $\mathrm{x}=110^{\circ}$
(b) $x=280^{\circ}$
(c) $x=100^{\circ}$
(d) $\mathrm{x}=50^{\circ}$
(e) $x=70^{\circ}$

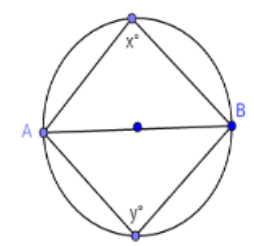

3. $\mathrm{O}$ is the centre of the circle, where $<\mathrm{QRS}=62$. Find the value of $<\mathrm{SQR}$.
(a) $28^{\circ}$
(b) $62^{\circ}$
(c) $90^{\circ}$
(d) $45^{\circ}$
(e) $31^{\circ}$

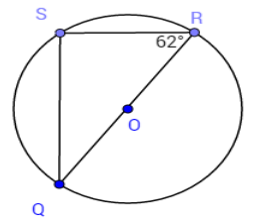


4. If $\mathrm{O}$ is the centre of the circle through points $\mathrm{L}, \mathrm{M}$ and $\mathrm{N}$. If $\angle \mathrm{MLN}=74^{\circ}$ and $<\mathrm{MNL}=39^{\circ}$. Calculate $<\mathrm{LON}$.
(a) $74^{\circ}$
(b) $39^{\circ}$
(c) $134^{\circ}$
(d) $67^{\circ}$
(e) $113^{\circ}$

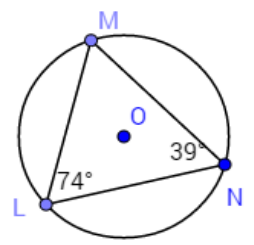

5. Find the value of $\mathrm{x}$ if $\mathrm{O}$ is the centre of the circle, $\angle \mathrm{POQ}=80^{\circ}$ and $\angle \mathrm{PRQ}=5 \mathrm{x}^{0}$.
(a) $8^{\circ}$
(b) $20^{\circ}$
(c) $40^{\circ}$
(d) $16^{\circ}$
(e) $10^{\circ}$

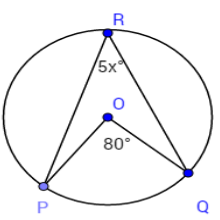

6. $\mathrm{PQ}$ is a diameter of the circle $\mathrm{PMQN}$ with circle $\mathrm{O}$. If $\angle \mathrm{PQM}=63^{\circ}$, find $\angle \mathrm{MNQ}$.
(a) $90^{\circ}$
(b) $63^{\circ}$
(c) $37^{\circ}$
(d) $27^{\circ}$
(e) $45^{\circ}$

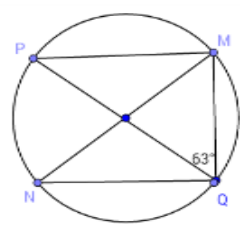

7. $\mathrm{PQR}$ is a circle with centre $\mathrm{O}, \angle \mathrm{QPR}=50^{\circ}, \angle \mathrm{PQO}=30^{\circ}$ and $\angle \mathrm{ORP}=\mathrm{M}$. Find $\mathrm{M}$.
(a) $30^{\circ}$
(b) $70^{\circ}$
(c) $25^{\circ}$
(d) $15^{\circ}$
(e) $20^{\circ}$

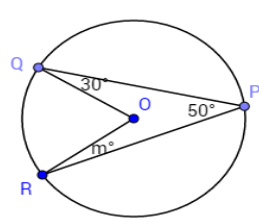

8. Find $\angle \mathrm{PQS}$, if $\mathrm{PQRS}$ is a circle in which $\angle \mathrm{PRQ}=54^{\circ}$ and $\angle \mathrm{SPQ}=97^{\circ}$.
(a) $64^{0}$
(b) $97^{0}$
(c) $29^{\circ}$
(d) $58^{0}$
(e) $68^{0}$

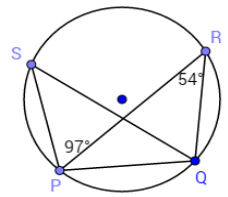

9. Find $<\mathrm{PQR}$ in the figure below;
(a) $117^{0}$
(b) $234^{0}$
(c) $54^{0}$
(d) $79^{0}$
(e) $63^{0}$

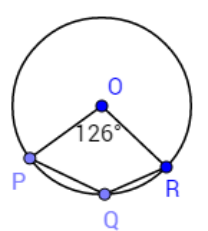

10. The diagram, $\mathrm{O}$ is the centre of the circle where $\mathrm{BD}$ and $\mathrm{AC}$ are straight lines. Angle $\mathrm{BOC}=124^{\circ}$. Find the value of the angle marked ' $x$ '.
(a) $62^{\circ}$
(b) $56^{0}$
(c) $82^{0}$
(d) $31^{0}$
(e) $28^{0}$

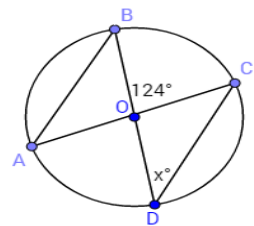

11. Line ETF is a tangent to the circle at $\mathrm{T}$. What is the size of $<\mathrm{ATB}$.
(a) $62^{0}$
(b) $66^{0}$
(c) $52^{0}$
(d) $78^{\circ}$
(e) $33^{0}$

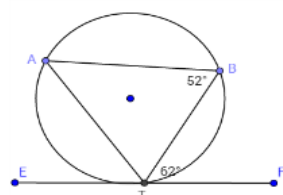



12. Find $<P R Q$ in the figure below;
(a) $94^{0}$
(b) $54^{0}$
(c) $48^{0}$
(d) $24^{0}$
(e) $38^{0}$

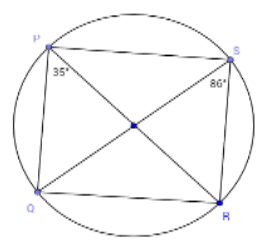

13. In the figure below, $\mathrm{O}$ is the centre of the circle. $/ \mathrm{OQ} /=/ \mathrm{OR} /$ and angle $\mathrm{PQR}=68^{\circ}$. Calculate angle $\mathrm{PRO}$, while $/ \mathrm{PQ} /$ is the diameter. (a) $68^{\circ}$ (b) $34^{\circ}$ (c) $56^{\circ}$ (d) $38^{\circ}$ (e) $22^{0}$

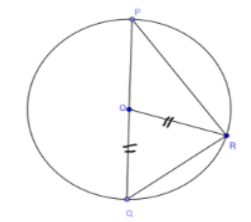

14. Line $\mathrm{PQX}$ is a tangent to the circle QRS. Calculate $<\mathrm{SQX}$.

(a) $77^{\circ}$ (b) $103^{\circ}$ (c) $66^{\circ}$ (d) $64^{\circ}$ (e) $74^{0}$

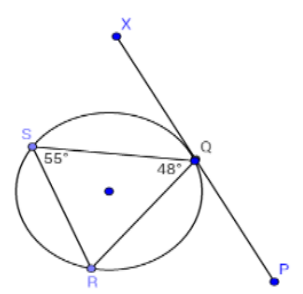

15. In the figure below $\mathrm{A}, \mathrm{B}$, and $\mathrm{C}$ are points in the circumference of the circle and $\mathrm{O}$ is the centre. Calculate the angle $\mathrm{BAC}$ and given that $\angle \mathrm{OBC}=25^{\circ}$.

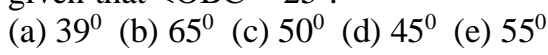

